\title{
Discontinuation of Biologic Therapy in Rheumatoid Arthritis: Analysis from the Corrona RA Registry
}

Vibeke Strand · Paul Miller - Setareh A. Williams - Katherine Saunders •

Shannon Grant · Joel Kremer

Received: May 26, 2017 / Published online: August 22, 2017

(C) The Author(s) 2017. This article is an open access publication

\section{ABSTRACT}

Introduction: Despite the availability of multiple effective therapies, discontinuation/switching of treatment is common for many patients with rheumatoid arthritis (RA). This study was designed to examine initiation of biologic disease-modifying anti-rheumatic drugs (bDMARDs) within the Consortium of Rheumatology Researchers of North America

Enhanced content To view enhanced content for this article go to http://www.medengine.com/Redeem/ 01FBF0607672C6CF.

V. Strand

Division of Immunology/Rheumatology, Stanford University School of Medicine, Portola Valley, CA, USA

P. Miller

Payer \& Real World Evidence, AstraZeneca,

Macclesfield, UK

S. A. Williams

Global Medical Affairs, AstraZeneca, Gaithersburg,

MD, USA

K. Saunders

Corrona LLC, Southborough, MA, USA

S. Grant

Axio LLC, Seattle, WA, USA

J. Kremer

Albany Medical College and the Center for

Rheumatology, Albany, NY, USA
(Corrona) RA Registry, and characterize reasons for discontinuation.

Methods: Inclusion criteria were: Corrona-registered adults ( $\geq 18$ years) with RA (2002-2011); age of RA onset: $\geq 16$ years; $\geq 6$ months' follow-up after initiation of first/subsequent bDMARD. Patients receiving both tumor necrosis factor antagonists and non-TNF antagonists were included. Treatment discontinuation was defined as first report of stopping initial therapy or initiation of new bDMARD at/between visits, using a follow-up physician questionnaire.

Results: Overall, 6209 patients met inclusion criteria and $80.7 \%$ received TNF antagonists.

Present Address:

P. Miller ( $\varangle)$

Miller Economics Ltd, Alderley Edge, Cheshire, UK e-mail: drpsjmiller@gmail.com

Present Address:

S. A. Williams

Radius Health, Inc, Wayne, PA, USA

Present Address:

S. Grant

Fred Hutchinson Cancer Research Center, Seattle, WA, USA 
Median time to discontinuation/change of therapy was 25.1 months (26.5 months with TNF antagonists vs. 20.5 months with non-TNF antagonists; log-rank $p<0.0001$ ); 82.2, 67.3, and $51.1 \%$ of patients remained on therapy at 6 , 12 , and 24 months, respectively. Reasons for discontinuation were captured for $49.2 \%$ of patients, including: loss of efficacy (35.8\%); physician preference $(27.8 \%)$; safety $(20.1 \%)$; patient preference (17.9\%); and no access to treatment $(9.0 \%)$. Baseline factors with greatest correlation to discontinuation were modified Health Assessment Questionnaire scores, patient-reported anxiety/depression, initiation of bDMARD treatment in 2007-2010 versus 2002-2003, and Clinical Disease Activity Index scores.

Conclusions: Almost one-third of patients in the US discontinue currently available bDMARD therapies for RA by 12 months and almost half by 24 months, most commonly due to loss of efficacy.

Funding: Corrona LLC and MedImmune.

Keywords: Anti-TNF; DAS28; Disease activity; Rheumatoid arthritis

\section{INTRODUCTION}

During the past 15 years, major paradigm shifts have occurred in the treatment of rheumatoid arthritis (RA), related in large part to the introduction of biologic disease-modifying antirheumatic drugs (bDMARDs) and earlier initiation of conventional synthetic DMARDs, which have demonstrated substantial benefits [1-5].

RA is a chronic and debilitating disease which negatively impacts patients' functional and overall health status, and reduces quality of life $[6,7]$. In some patients, the promising therapeutic benefits of currently available bDMARDs, demonstrated in randomized controlled trials (RCTs), may be undermined by poor adherence and/or early discontinuation of treatment in clinical practice [8]. Frequent interruptions of treatment and switching of therapies makes longer-term clinical management of RA more challenging, results in greater costs for healthcare systems, and requires clinicians to develop sequential treatment strategies based on limited clinical and economic evidence [5, 9-14].

The extent to which patients with RA in routine clinical practice settings are cycling through bDMARDs has been characterized by some European registries, which have reported 1 -year discontinuation rates of $25-54 \%$ for tumor necrosis factor antagonists [15] and 25-55\% for other bDMARDs [16]. Two-year discontinuation rates of $35-50 \%$ for TNF antagonists have also been reported $[15,17,18]$. There are currently no RCTs fulfilling inclusion criteria for switching between bDMARDs [19].

In the US, few studies have examined the continuation of bDMARDs in patients with RA $[8,20-25]$. The majority have focused on patients from large US private health plans or managed care organizations, which generally exclude patients who are very poor, sick, disabled, or old [26]. Therefore, there is a need for further investigation into the rates and reasons for bDMARD discontinuations.

The Consortium of Rheumatology Researchers of North America (Corrona) RA Registry is an independent database of patients with RA established in 2001, which includes clinical, laboratory, imaging, medication, and safety data $[27,28]$. To date, Corrona has collected over 90,000 patient-years of data from over 600 participating rheumatologists throughout the US (both academic and private) [28].

This observational study was designed to examine initiation of bDMARDs in patients with RA within the Corrona database, and to characterize reasons for treatment discontinuations.

\section{METHODS}

A study protocol was developed in line with the Agency for Healthcare Research and Quality (AHRQ) guidelines for observational studies [29]. 


\section{Study Population}

Figure 1 shows the patient population of the Corrona database. Data were collected from patients and their rheumatologists using questionnaires that gathered information on: disease duration, prognostic information, physician- and patient-determined standardized disease severity and activity measures, medical comorbidities, use of medications (including DMARDs), laboratory values, and adverse events (AEs). Follow-up assessments were requested at 4-month intervals and were completed during routine clinical consultations.

Approvals for participation in Corrona were obtained from the respective institutional review boards of the participating academic sites and from a central institutional review board for private practice sites. Researchers had access only to de-identified patient data, and patient anonymity and confidentiality were safeguarded in compliance with the Health Insurance Portability and Accountability Act (HIPAA).

\section{Study Design}

Patients with RA who joined Corrona during the calendar years 2002-2011 were included in this study. Inclusion criteria were: adult patients (aged $\geq 18$ years); adult-onset RA (aged $\geq 16$ years); first bDMARD on-study; $\geq 6$ months' follow-up available after initiation of first or subsequent bDMARD therapy (defined as a visit $\geq 180$ days after the initiation of bDMARD). The bDMARDs included TNF antagonists (adalimumab, certolizumab pegol, etanercept, golimumab, and infliximab) and non-TNF antagonists (abatacept, anakinra, rituximab, and tocilizumab).

The primary outcome was time to discontinuation of therapy, defined as the first report of stopping initial therapy or initiation of a new bDMARD at/between visits using a follow-up physician questionnaire. As many as three reasons for discontinuation were captured, which were not mutually exclusive. Short-term ( $<12$ months after induction) and long-term ( $\geq 12$ months after induction) discontinuation were also investigated.

Reasons for discontinuation reported by the physician were summarized for the overall population and for cohorts defined by follow-up duration, bDMARD class initiated, history of bDMARD treatment, and concurrent DMARD treatment. Reasons were categorized as follows: efficacy (loss of efficacy, disease flare, inadequate initial response, failure to maintain initial response); safety (toxicity, lymphoma/malignancy, serious $\mathrm{AE}$, infection, minor $\mathrm{AE}$ ); physician preference (patient doing well, treatment no longer required); patient preference (patient preference, frequency of

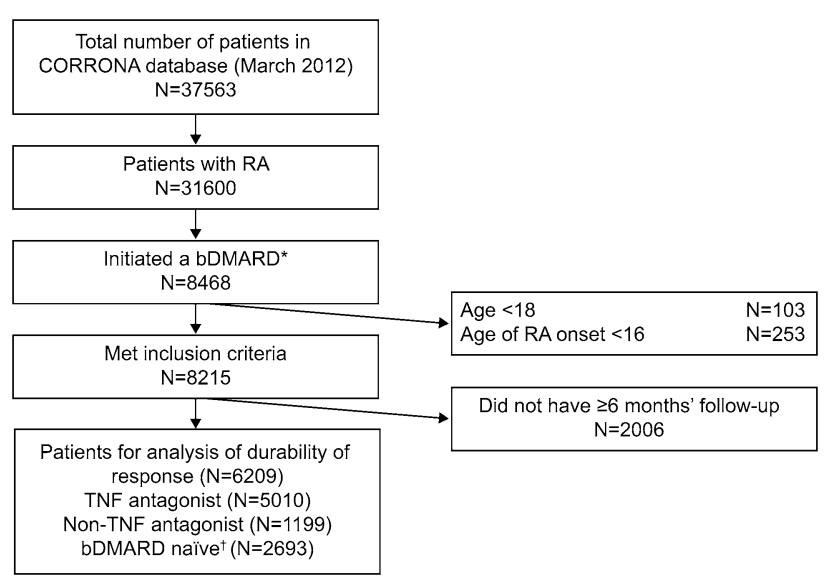

Fig. 1 Corrona patient population. ${ }^{*}$ bDMARD not started and dropped between visits. ${ }^{\dagger}$ At start of treatment. $b D M A R D$ biologic disease-modifying anti-rheumatic drug, $R A$ rheumatoid arthritis 
administration, fear of future AE); access (formulary restriction, lack of insurance, cost/insurance); other (recent journal report, recent meeting report, recent lecture, withdrawn by US Food and Drug Administration, peer suggestion, other reason).

\section{Statistical Analysis}

For the analysis of time-to-change in therapy, Kaplan-Meier estimates of time to discontinuation were conducted for all initiators; an unadjusted Kaplan-Meier product limit was used to estimate durability rates at 6 and 12 months. The influence of baseline covariates of clinical interest on risk-of-treatment change and duration of response was investigated using Cox proportional hazards regression models. Univariate hazard ratios were used to explore the association between discontinuation and initiator characteristics. Hazard ratios for continuous characteristics are for a 1-unit increase.

\section{RESULTS}

\section{Patient Demographics}

A total of 6209 patients who enrolled in the Corrona database between 2002 and 2011 met the inclusion criteria and were included in this analysis. Mean duration of follow-up was 37.2 months. Patient demographic and disease characteristics at initiation of therapy are detailed in Table 1 . Overall, mean age was 57.6 years, $78.3 \%$ of patients were women, mean duration of RA was 10.7 years, mean Clinical Disease Activity Index (CDAI) was 16, mean number of swollen and tender joints was 4.9 , and mean modified Health Assessment Questionnaire (mHAQ) was 0.5. Patients in the non-TNF antagonist cohort were older and with longer disease duration and greater disease activity scores compared with patients initiating TNF antagonists.

\section{Treatment Initiation}

Overall, $80.7 \%$ of patients initiated bDMARD treatment with TNF antagonists; 19.3\% with
non-TNF antagonists (Table 1). Etanercept, adalimumab, and infliximab accounted for $>95 \%$ of TNF antagonist use, while abatacept and rituximab comprised almost $90 \%$ of non-TNF antagonist use. At initiation, $43.4 \%$ of patients were bDMARD-naïve and $42.3 \%$ in the non-TNF antagonist cohort had received $\geq 2$ prior bDMARDs.

\section{Durability of Response}

Median time to discontinuation or change of treatment was 25.1 months (Fig. 2a). Patients initiating non-TNF antagonist had lower durability rates versus those initiating TNF antagonists (log-rank $p<0.0001$ ); median time to discontinuation was 26.5 months with TNF antagonists $(N=5010)$ versus 20.5 months $(N=1199)$ with non-TNF antagonists (Fig. 2b). Patients who were bDMARD-naïve $(N=2693)$ had numerically greater durability of response to the first bDMARD treatment compared with patients previously treated with bDMARDs, although this difference was not significant ( $\log$-rank $p=0.0601$; data not shown). Durability curves were not significantly different between patients receiving bDMARDs as monotherapy and those receiving bDMARDs in combination with other DMARDs (data not shown).

\section{Treatment Discontinuation}

Overall, $82.2,67.3$, and $51.1 \%$ of patients remained on initiated treatment at 6,12 , and 24 months, respectively (Fig. 2a). Proportions of patients receiving TNF antagonists remaining on initiated treatment at 6,12 , and 24 months were $82.5,68.2$, and $52.2 \%$, respectively, compared with $80.9,63.4$, and $46.0 \%$ for patients receiving non-TNF antagonists.

Reasons for treatment discontinuation were captured for $49.2 \%$ of patients $(1763 / 3584)$. Loss of efficacy was the most common reason for discontinuation (35.8\%), followed by physician preference $(27.8 \%)$, safety $(20.1 \%)$, patient preference $(17.9 \%)$, and lack of access to treatment (9.0\%) (Fig. 3a). Patients with longer follow-up were more likely to give reasons for 
Table 1 Patient characteristics at treatment initiation

$\begin{array}{lll}\text { All patients } & \text { Non-TNF } & \text { TNF antagonist } \\ (N=6209) & \text { antagonist } & (N=5010) \\ & (N=1199) & \end{array}$

Demographic and disease characteristics

Age, years, mean (SD)

Sex, female, \%

Race, white, \%

Work status, \%

Full-time

Part-time

Not working outside the home with pay

Current smoker, \%

Duration of RA, years, mean (SD)

CDAI, mean (SD)

Number of tender/swollen joints, mean (SD)

mHAQ, mean (SD)

Physician global assessment of disease activity, mean (SD)

Patient global assessment of disease activity, mean (SD)

Patient global assessment of pain severity, mean (SD)

Patient-reported anxiety/depression, \%

Clinical treatment characteristics

bDMARD initiated: TNF antagonist, \%

Etanercept

Adalimumab

Infliximab

Certolizumab pegol

Golimumab

bDMARD initiated: non-TNF antagonist, \%

Tocilizumab

Abatacept

Rituximab

Anakinra

Current use of DMARD at bDMARD initiation, \%
$57.6(12.8)$

78.3

88.9

37.0

9.9

52.2

14.8

$10.7(9.5)$

$16.0(13.2)$

$4.9(6.5) / 4.9(5.7) \quad 5.7(6.9) / 5.1(5.5)$

$0.5(0.5)$

$26.2(21.2)$

$35.6(26.3)$

$38.2(27.2)$

19.0

$0.5(0.5)$

28.5 (21.9)

40.5 (25.8)

$43.4(27.2)$

19.5

80.7

25.5

26.7

24.8

1.8

1.8

19.3

1.6

11.5

5.4

0.8

81.9
$-$

$-$

$-$

$-$

$-$

-

100

8.4

59.3

28.0

4.3

77.6
$57.2(12.8)$

77.9

88.4

38.5

9.9

50.7

15.3

10.3 (9.4)

15.6 (13.1)

$4.7(6.4) / 4.9(5.8)$

$0.4(0.5)$

$25.6(21.0)$

34.4 (26.3)

$36.9(27.0)$

18.8

100

31.7

33.1

30.8

2.2

2.2

$-$

$-$

$-$

$-$

-

83.0 
Table 1 continued

\begin{tabular}{|c|c|c|c|}
\hline & $\begin{array}{l}\text { All patients } \\
(N=6209)\end{array}$ & $\begin{array}{l}\text { Non-TNF } \\
\text { antagonist } \\
(N=1199)\end{array}$ & $\begin{array}{l}\text { TNF antagonist } \\
(N=5010)\end{array}$ \\
\hline \multicolumn{4}{|l|}{ Number of prior DMARDs, $\%$} \\
\hline 0 & 29.2 & 11.6 & 33.4 \\
\hline 1 & 27.5 & 19.3 & 29.4 \\
\hline 2 & 19.2 & 20.4 & 18.9 \\
\hline $3+$ & 24.2 & 48.7 & 18.3 \\
\hline \multicolumn{4}{|l|}{ Number of prior bDMARDs, \% } \\
\hline 0 & 43.4 & 20.2 & 48.9 \\
\hline 1 & 37.1 & 37.5 & 37.0 \\
\hline 2 & 13.0 & 23.7 & 10.4 \\
\hline $3+$ & 6.5 & 18.6 & 3.6 \\
\hline \multicolumn{4}{|l|}{ Number of prior TNF antagonist bDMARDs, \% } \\
\hline 0 & 44.9 & 23.7 & 50.0 \\
\hline 1 & 38.2 & 41.5 & 37.4 \\
\hline 2 & 13.2 & 24.3 & 10.6 \\
\hline $3+$ & 3.6 & 10.5 & 2.0 \\
\hline \multicolumn{4}{|c|}{ Number of prior non-TNF antagonist bDMARDs, \% } \\
\hline 0 & 91.7 & 76.9 & 95.2 \\
\hline 1 & 7.2 & 18.8 & 4.4 \\
\hline $2+$ & 1.2 & 4.3 & 0.4 \\
\hline Current use of prednisone: patient report, \% & 39.7 & 49.2 & 37.4 \\
\hline
\end{tabular}

bDMARD biologic disease-modifying anti-rheumatic drug, $C D A I$ Clinical Disease Activity Index, $m H A Q$ modified Health Assessment Questionnaire, $R A$ rheumatoid arthritis, $S D$ standard deviation

discontinuation, compared with those with shorter follow-up (Fig. 3b). Reasons for discontinuation between the TNF antagonist and non-TNF antagonist cohorts, between those who had previously received bDMARD treatment, and between those who were and were not receiving concurrent DMARD treatment were generally similar (Fig. 3c-e); however, the non-TNF antagonist group was more likely to discontinue due to loss of efficacy compared with the TNF antagonist group. In addition, patients who had previously received bDMARD treatment were more likely to discontinue due to loss of efficacy than those who were bDMARD-naïve.

Table 2 presents univariate hazard ratios exploring the association between discontinuation and baseline characteristics. Among the strongest predictors for discontinuation were mHAQ score, patient-reported anxiety/depression, year of bDMARD initiation (2007-2010 vs. 2002-2003), CDAI score, Disease Activity Score (DAS) 28, and number of prior DMARDs received. 

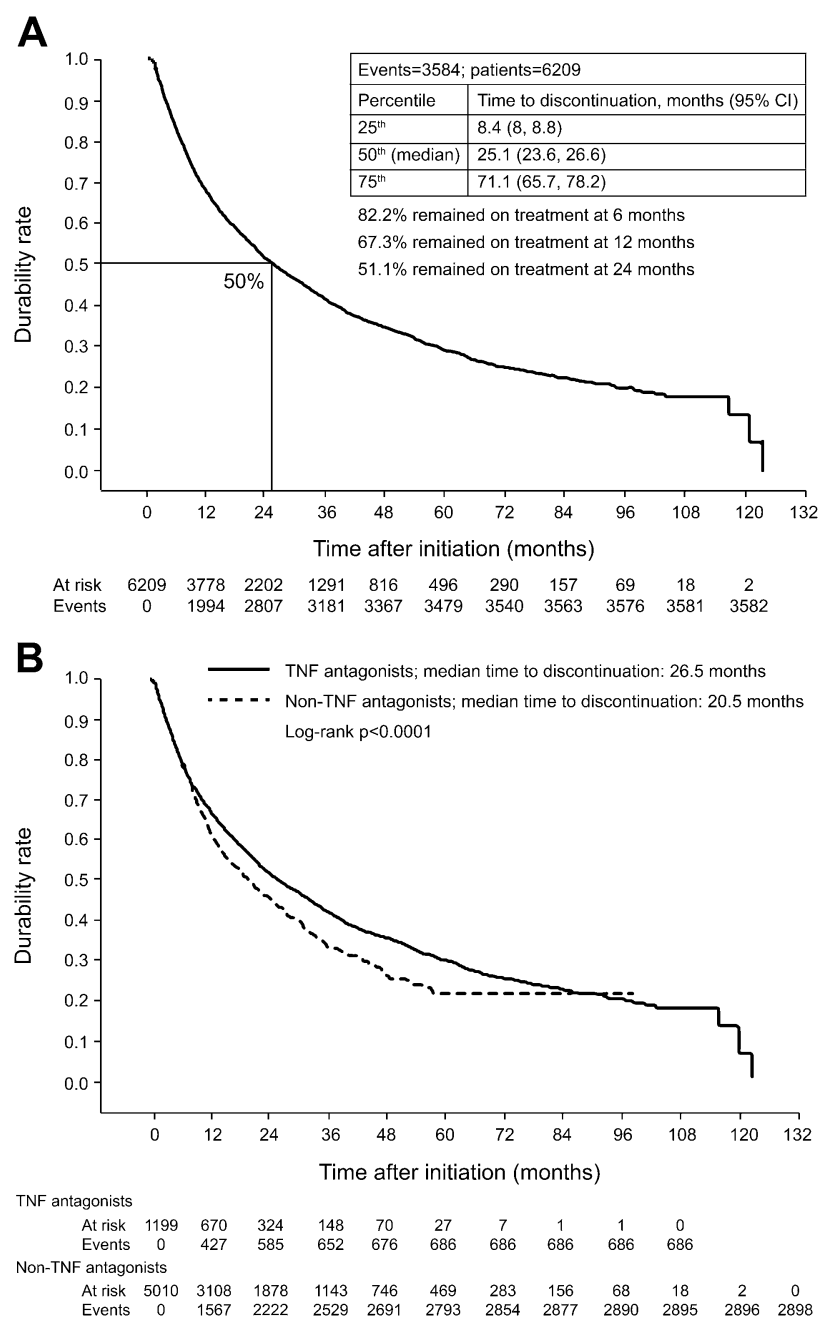

Fig. 2 Kaplan-Meier estimates of durability of response to first treatment (a) in the overall study population and (b) by bDMARD class initiated. $C I$ confidence interval

\section{DISCUSSION}

This study was a comprehensive evaluation of the initiation of bDMARDs for treatment of patients with RA, and associated rates and reasons for treatment discontinuation from patients within the US Corrona database. For the period of time included in this study (2002-2011), a large proportion of patients did not remain on their initiated bDMARD for $>24$ months. Approximately one-third of patients discontinued the initiated bDMARD treatment by 12 months, and half by 24 months. Median time to discontinuation was significantly longer for patients who received TNF antagonists compared with those who received non-TNF antagonists; however, recorded reasons for treatment discontinuation were similar between the two cohorts. Physicians frequently reported more than one reason for discontinuation. Overall, the reported reasons were multifactorial and reflected expectations on the part of both patients and physicians. Loss of efficacy was the most common reason for discontinuation and likely reflected switching of therapies.

Discontinuation rates, such as those shown in this study, present a challenge for the management of RA. Patients had received a bDMARD $\geq 6$ months, presumably indicating an 
Reason for discontinuation

a. Loss of efficacy

b. Safety

C. Physician preference

d. Patient preference

e. Access to treatment

\section{B}

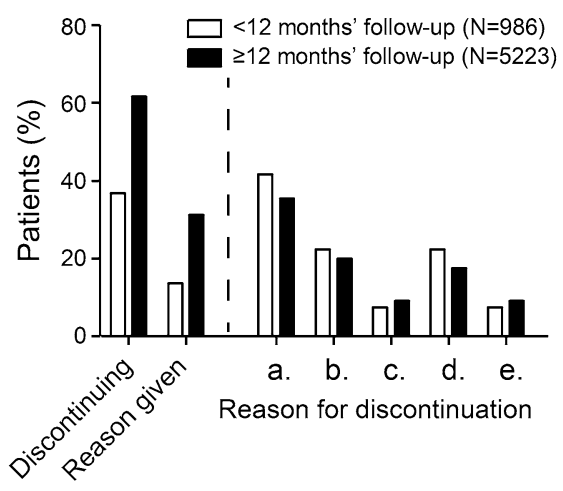

D

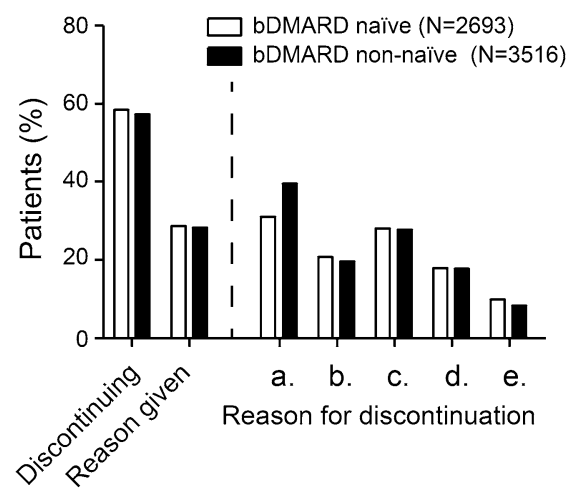

Fig. 3 Reasons given for discontinuation of treatment: $\mathbf{a}$ in overall population; $\mathbf{b}$ by follow-up duration; $\mathbf{c}$ by bDMARD class initiated; $\mathbf{d}$ by history of bDMARD

initial response to treatment; therefore, this practice does not appear to reflect the empiricism required for selecting bDMARD therapies, as no biomarkers are available to facilitate selection of specific treatment classes. Reasons for discontinuation were varied, and frequently multiple. It was decided to focus these analyses

\section{A}

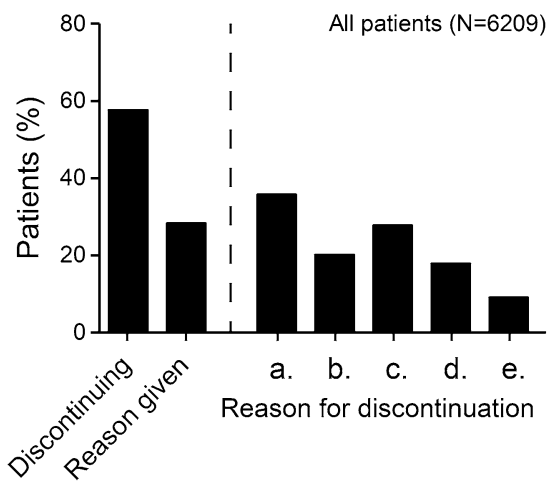

C

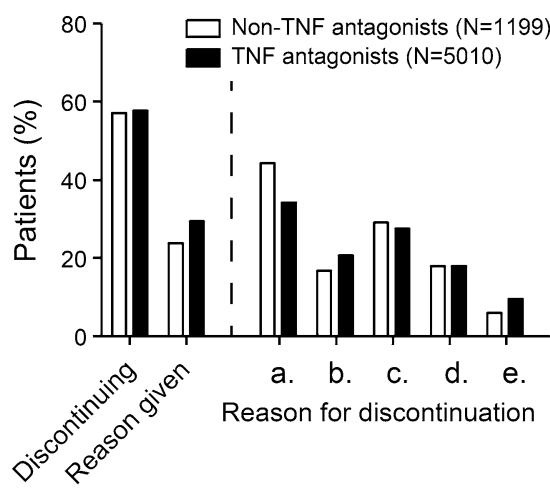

E

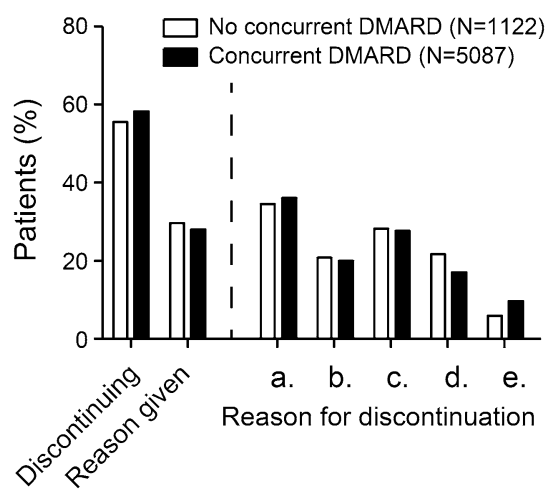

treatment; e by concurrent DMARD treatment. DDMARD biologic disease-modifying anti-rheumatic drug

on discontinuations-not differentiating between patients who switched treatment versus those who discontinued treatment altogether. Nonetheless, it is reasonable to assume additional healthcare resources may be required to manage such transitions and treatment changes. 
Table 2 Association between discontinuation and baseline characteristics (univariate proportional hazards models)

\begin{tabular}{|c|c|c|c|c|c|}
\hline \multirow[t]{2}{*}{ Parameter } & \multirow[t]{2}{*}{ Level } & \multicolumn{2}{|l|}{ Non-TNF antagonist } & \multicolumn{2}{|l|}{ TNF antagonist } \\
\hline & & HR (95\% CI) & $p$ value & HR (95\% CI) & $p$ value \\
\hline Age & & $0.999(0.993,1.005)$ & 0.8177 & $1.000(0.997,1.003)$ & 0.8834 \\
\hline Sex & Female & $0.963(0.799,1.160)$ & 0.6903 & $1.059(0.969,1.158)$ & 0.2077 \\
\hline Race versus white & $\begin{array}{c}\text { Black/African } \\
\text { American }\end{array}$ & $1.086(0.757,1.559)$ & 0.3148 & $1.097(0.940,1.280)$ & 0.7041 \\
\hline \multirow[t]{2}{*}{ Work status versus full-time } & Part-time & $0.946(0.713,1.254)$ & 0.8748 & $1.140(1.004,1.294)$ & 0.0018 \\
\hline & $\begin{array}{l}\text { Not working outside } \\
\text { the home with pay }\end{array}$ & $1.014(0.857,1.199)$ & & $1.149(1.062,1.243)$ & \\
\hline Current smoker & Yes & $1.164(0.933,1.451)$ & 0.1792 & $1.099(0.994,1.214)$ & 0.0659 \\
\hline Duration of RA & & $0.997(0.989,1.004)$ & 0.3928 & $1.002(0.998,1.006)$ & 0.2595 \\
\hline CDAI & & $1.015(1.010,1.021)$ & $<0.0001$ & $1.015(1.012,1.017)$ & $<0.0001$ \\
\hline DAS28 & & $1.116(1.032,1.206)$ & 0.0057 & $1.115(1.076,1.155)$ & $<0.0001$ \\
\hline Number of tender joints & & $1.023(1.010,1.036)$ & 0.0004 & $1.018(1.012,1.024)$ & $<0.0001$ \\
\hline Number of swollen joints & & $1.030(1.020,1.040)$ & $<0.0001$ & $1.025(1.020,1.031)$ & $<0.0001$ \\
\hline mHAQ & & $1.387(1.208,1.592)$ & $<0.0001$ & $1.456(1.356,1.563)$ & $<0.0001$ \\
\hline $\begin{array}{l}\text { Physician global assessment of } \\
\text { disease activity }\end{array}$ & & $1.009(1.006,1.012)$ & $<0.0001$ & $1.009(1.007,1.011)$ & $<0.0001$ \\
\hline $\begin{array}{l}\text { Patient global assessment of } \\
\text { disease activity }\end{array}$ & & $1.009(1.006,1.012)$ & $<0.0001$ & $1.010(1.008,1.011)$ & $<0.0001$ \\
\hline $\begin{array}{l}\text { Patient global assessment of } \\
\text { pain severity }\end{array}$ & & $1.010(1.007,1.012)$ & $<0.0001$ & $1.009(1.008,1.011)$ & $<0.0001$ \\
\hline $\begin{array}{l}\text { Patient-reported anxiety/ } \\
\text { depression }\end{array}$ & & $1.225(1.022,1.470)$ & 0.0285 & $1.289(1.179,1.410)$ & $<0.0001$ \\
\hline \multirow{8}{*}{$\begin{array}{l}\text { Year of initiation versus } \\
2002-2003\end{array}$} & 2004 & $0.386(0.161,0.922)$ & $<0.0001$ & $1.011(0.856,1.193)$ & 0.0007 \\
\hline & 2005 & $1.128(0.511,2.490)$ & & $1.140(0.966,1.345)$ & \\
\hline & 2006 & $0.405(0.232,0.708)$ & & $1.046(0.885,1.237)$ & \\
\hline & 2007 & $0.267(0.153,0.468)$ & & $1.253(1.060,1.483)$ & \\
\hline & 2008 & $0.256(0.146,0.449)$ & & $1.295(1.089,1.540)$ & \\
\hline & 2009 & $0.310(0.179,0.536)$ & & $1.197(1.014,1.413)$ & \\
\hline & 2010 & $0.288(0.166,0.501)$ & & $1.289(1.086,1.530)$ & \\
\hline & 2011 & $0.321(0.177,0.581)$ & & $0.980(0.758,1.267)$ & \\
\hline \multirow{3}{*}{$\begin{array}{l}\text { Number of prior DMARDs } \\
\text { versus } 0\end{array}$} & 1 & $0.978(0.735,1.301)$ & 0.0837 & $1.156(1.053,1.270)$ & $<0.0001$ \\
\hline & 2 & $0.947(0.716,1.254)$ & & $1.160(1.043,1.290)$ & \\
\hline & $3+$ & $1.179(0.922,1.509)$ & & $1.403(1.265,1.556)$ & \\
\hline
\end{tabular}


Table 2 continued

\begin{tabular}{|c|c|c|c|c|c|}
\hline \multirow[t]{2}{*}{$\overline{\text { Parameter }}$} & \multirow[t]{2}{*}{ Level } & \multicolumn{2}{|l|}{ Non-TNF antagonist } & \multicolumn{2}{|l|}{ TNF antagonist } \\
\hline & & HR (95\% CI) & $p$ value & $\overline{\text { HR }(95 \% \mathrm{CI})}$ & $p$ value \\
\hline bDMARD-naïve & Yes & $0.918(0.761,1.108)$ & 0.3747 & $0.973(0.905,1.047)$ & 0.4656 \\
\hline \multirow{3}{*}{$\begin{array}{l}\text { Number of prior bDMARDs } \\
\text { versus } 0\end{array}$} & 1 & $1.037(0.842,1.278)$ & 0.3620 & $0.993(0.917,1.075)$ & 0.0060 \\
\hline & 2 & $1.078(0.859,1.352)$ & & $1.056(0.931,1.198)$ & \\
\hline & $3+$ & $1.223(0.962,1.556)$ & & $1.394(1.149,1.691)$ & \\
\hline \multirow{3}{*}{$\begin{array}{l}\text { Number of prior TNF } \\
\text { antagonist bDMARDs versus } \\
0\end{array}$} & 1 & $1.121(0.922,1.364)$ & 0.1219 & $0.989(0.914,1.070)$ & 0.0225 \\
\hline & 2 & $1.095(0.878,1.364)$ & & $1.076(0.950,1.219)$ & \\
\hline & $3+$ & $1.389(1.061,1.819)$ & & $1.453(1.120,1.886)$ & \\
\hline \multirow{2}{*}{$\begin{array}{l}\text { Number of prior non-TNF } \\
\text { antagonist bDMARDs versus } \\
0\end{array}$} & 1 & $1.017(0.835,1.237)$ & 0.9172 & $1.228(1.035,1.456)$ & 0.0096 \\
\hline & $2+$ & $1.083(0.730,1.607)$ & & $1.766(1.001,3.114)$ & \\
\hline $\begin{array}{l}\text { Current use of prednisone } \\
\text { (OCS) }\end{array}$ & Yes & $0.933(0.800,1.089)$ & 0.3812 & $1.130(1.045,1.222)$ & 0.0022 \\
\hline Current use of leflunomide & Yes & $1.025(0.812,1.294)$ & 0.8378 & $1.170(1.044,1.310)$ & 0.0069 \\
\hline Current use of methotrexate & Yes & $1.138(0.975,1.327)$ & 0.1004 & $0.901(0.833,0.974)$ & 0.0086 \\
\hline
\end{tabular}

bDMARD biologic disease-modifying anti-rheumatic drug, CDAI Clinical Disease Activity Index, $C I$ confidence interval, $D A S$ Disease Activity Score, $H R$ hazard ratio, $m H A Q$ modified Health Assessment Questionnaire, OCS oral corticosteroid, $R A$ rheumatoid arthritis

The decision regarding how to manage patients who do not have a durable response to the initiated bDMARD treatment is challenging. Rheumatologists may consider several alternative approaches, including switching to a different agent in the same class (e.g., from one TNF antagonist to another), switching to a different class of bDMARD, or modifying concomitant DMARD treatment. Several professional associations, including the American College of Rheumatology [30] and the Consensus Group on Advances in Targeted Therapy [31], recommend switching between TNF antagonists when the first agent is associated with an inadequate response or poor tolerability, based on evidence derived primarily from observational studies. However, the likelihood of response to subsequent bDMARDs decreases as the number of prior treatments increases [32]. Changing bDMARD class is also an option in patients who discontinue due to lack of efficacy. Data from published RCTs have confirmed that non-TNF antagonists are effective in patients with inadequate responses to $>1$ TNF antagonist [33-36].

Results of this study are consistent with recent findings from national registries and other longitudinal observational studies, which indicate that 12-month survival rates for use of bDMARDs, such as TNF antagonists, are $65-83 \%$ [5]. In this current study, reasons for discontinuation could be determined in approximately $50 \%$ of patients, whereas previous US-based studies have been unable to ascertain these reasons. Factors with the strongest correlations to treatment discontinuation were higher CDAI and mHAQ scores, as well as patient reports of anxiety/depression. These reasons may be linked indirectly (patients with more active disease may be harder to treat and may be more likely to be depressed) [37], or directly (patients may experience depression as a result of ineffective treatment) to treatment discontinuation. 
Of interest, patients who initiated bDMARD treatment in the period 2007-2010 were significantly more likely to discontinue treatment, compared with those in the base period (2002-2003). This may be explained either by increased availability of bDMARD treatment alternatives, or by increased patient and physician experience with these therapies in 2007-2010. Although few patients initiated treatment with certolizumab pegol, golimumab, or tocilizumab, more recent availability of these bDMARDs may have impacted decisions to switch therapies.

Several limitations need to be considered when interpreting the results of this study. Corrona is a voluntary database and therefore patients with RA at any one site, or patients treated consecutively, are not enrolled automatically. Nonetheless, a recent study compared the characteristics of patients participating in the Corrona registry with Medicare patients of the same age range and demonstrated that Corrona participants are representative of the patient population with RA in the US. The demographics and comorbidity profiles of Corrona participants and Medicare patients are very similar and, although Corrona participants are somewhat more likely to receive bDMARDs or DMARDs compared with Medicare patients, this difference is small (85\% for Corrona participants vs. $73 \%$ for Medicare patients) [38]. As this study focused on time to discontinuation as the primary outcome, data related to dose or dose frequency adjustments were not evaluated. Furthermore, the length of time that patients discontinued bDMARD treatment could not be distinguished. However, treatment holidays were an exception to the treatment paradigm at the time, so discontinuation of one medication would typically result in an immediate switch to another.

While reasons for discontinuation (loss of efficacy, physician preference, safety, patient preference, and no access to treatment) have been provided here, evaluation of the future management of patients, including analyses of treatment switching data, is beyond the scope of the present report. Previous studies have demonstrated that patients with RA who experience treatment failures with one bDMARD (TNF antagonist) frequently switch to another [10, 39].

\section{CONCLUSIONS}

In conclusion, this study examined initiation of bDMARD therapies within the US Corrona database between 2002 and 2011, and characterized reasons for bDMARD discontinuation. Results highlight significant discontinuation rates during the investigated time period, with the most common reason being loss of bDMARD efficacy.

\section{ACKNOWLEDGEMENTS}

This study was sponsored by Corrona LLC, Southborough, MA, USA. The Corrona RA registry has been supported through contracted subscriptions in the last 2 years by AbbVie (Chicago, IL, USA), Amgen (Thousand Oaks, CA, USA), AstraZeneca (Melbourn, Hertfordshire, UK), Genentech (San Francisco, CA, USA), Horizon Pharma (Dublin, Ireland), Eli Lilly (Indianapolis, IN, USA), Janssen Biotech (Horsham Township, PA, USA), Novartis (Basel, Switzerland), Pfizer (New York City, NY, USA), Vertex (Boston, MA, USA), and UCB (Brussels, Belgium). Medical writing support was full$y$-funded by MedImmune, a member of the AstraZeneca Group in accordance with Good Publication Practice (GPP3) guidelines (http:// www.ismpp.org/gpp3). MedImmune also funded the publication charges.

We acknowledge the editorial services of Ellie Ling, PhD (PAREXEL International, Wicker House, Worthing, UK) at initial development and medical writing support of Elspeth Stewart, PhD, QXV Comms, Macclesfield, UK (an Ashfield company, part of UDG Healthcare plc), which was fully funded by MedImmune, a member of the AstraZeneca Group in accordance with Good Publication Practice (GPP3) guidelines (http://www.ismpp.org/gpp3).

All named authors meet the International Committee of Medical Journal Editors (ICMJE) criteria for authorship of this manuscript, take 
responsibility for the integrity of the work as a whole, and have given final approval to the version to be published.

Disclosures. V. Strand is a consultant for Corrona LLC, Alder, Protagen, AbbVie, Amgen, AstraZeneca, Biotest, Bristol-Myers Squibb, Crescendo/Myriad Genetics, EMDSerono, Genentech/Roche, GlaxoSmithKline, Hospira, Janssen, Lilly, Novartis, Pfizer, Regeneron, Sandoz, Sanofi, UCB, and Vertex, and has served on advisory boards for AbbVie, Amgen, AstraZeneca, Biotest, Bristol-Myers Squibb, Celltrion, Crescendo/Myriad Genetics, EMDSerono, Genentech/Roche, GlaxoSmithKline, Hospira, Janssen, Lilly, Novartis, Pfizer, Regeneron, Sandoz, Sanofi, UCB, and Vertex.

P. Miller is a previous employee of AstraZeneca. SA Williams is a previous employee of AstraZeneca. K Saunders is an employee of Corrona LLC. S Grant is a previous employee of Axio LLC (consultant for Corrona LLC), and is currently an employee of the Fred Hutchinson Cancer Research Center and a consultant to Axio LLC. J Kremer is a shareholder and employee of Corrona LLC and has received grants from AbbVie, Amgen, Genetech, Lilly, and Pfizer, and consulting fees from AbbVie, Amgen, Genentech, Lilly, Pfizer, Bristol-Myers Squibb, and MedImmune.

Compliance with Ethics Guidelines. The Corrona RA Registry has IRB approval through the New England IRB.

Open Access. This article is distributed under the terms of the Creative Commons Attribution-NonCommercial 4.0 International License (http://creativecommons.org/licenses/ by-nc/4.0/), which permits any noncommercial use, distribution, and reproduction in any medium, provided you give appropriate credit to the original author(s) and the source, provide a link to the Creative Commons license, and indicate if changes were made.

\section{REFERENCES}

1. Aaltonen KJ, Virkki LM, Malmivaara A, Konttinen YT, Nordstrom DC, Blom M. Systematic review and meta-analysis of the efficacy and safety of existing TNF blocking agents in treatment of rheumatoid arthritis. PLoS One. 2012;7(1):e30275. doi:10.1371/ journal.pone.0030275.

2. Nam JL, Winthrop KL, van Vollenhoven RF, Pavelka $\mathrm{K}$, Valesini G, Hensor EM, et al. Current evidence for the management of rheumatoid arthritis with biological disease-modifying antirheumatic drugs: a systematic literature review informing the EULAR recommendations for the management of RA. Ann Rheum Dis. 2010;69(6):976-86. doi:10.1136/ard. 2009.126573.

3. Singh JA, Christensen R, Wells GA, Suarez-Almazor ME, Buchbinder R, Lopez-Olivo MA, et al. Biologics for rheumatoid arthritis: an overview of Cochrane reviews. Sao Paulo Med J. 2010;128(5):309-10.

4. Smolen JS. Treat-to-target: rationale and strategies. Clin Exp Rheumatol. 2012;30(4 Suppl 73):S2-6.

5. Reynolds A, Koenig AS, Bananis E, Singh A. When is switching warranted among biologic therapies in rheumatoid arthritis? Expert Rev Pharmacoecon Outcomes Res. 2012;12(3):319-33. doi:10.1586/erp. 12.27 .

6. Russell AS. Quality-of-life assessment in rheumatoid arthritis. Pharmacoeconomics. 2008;26(10):831-46.

7. Scott DL, Wolfe F, Huizinga TW. Rheumatoid arthritis. Lancet. 2010;376(9746):1094-108. doi:10. 1016/S0140-6736(10)60826-4.

8. Li P, Blum MA, Von FJ, Hennessy S, Doshi JA. Adherence, discontinuation, and switching of biologic therapies in Medicaid enrollees with rheumatoid arthritis. Value Health. 2010;13(6):805-12. doi:10.1111/j.1524-4733.2010.00764.x.

9. Alivernini S, Laria A, Gremese E, Zoli A, Ferraccioli G. ACR70-disease activity score remission achievement from switches between all the available biological agents in rheumatoid arthritis: a systematic review of the literature. Arthritis Res Ther. 2009;11(6):R163. doi:10.1186/ar2848.

10. Hyrich KL, Lunt M, Watson KD, Symmons DP, Silman AJ. Outcomes after switching from one anti-tumor necrosis factor alpha agent to a second anti-tumor necrosis factor alpha agent in patients with rheumatoid arthritis: results from a large UK national cohort study. Arthritis Rheum. 2007;56(1):13-20. doi:10.1002/art.22331.

11. Jamnitski A, Bartelds GM, Nurmohamed MT, van Schouwenburg PA, van Schaardenburg D, Stapel SO, et al. The presence or absence of antibodies to infliximab or adalimumab determines the outcome of switching to etanercept. Ann Rheum Dis. 2011;70(2):284-8. doi:10.1136/ard.2010.135111. 
12. Lloyd S, Bujkiewicz S, Wailoo AJ, Sutton AJ, Scott D. The effectiveness of anti-TNF-alpha therapies when used sequentially in rheumatoid arthritis patients: a systematic review and meta-analysis. Rheumatology (Oxford). 2010;49(12):2313-21. doi:10.1093/ rheumatology/keq169.

13. Soliman MM, Hyrich KL, Lunt $M$, Watson $K D$, Symmons DP, Ashcroft DM. Rituximab or a second anti-tumor necrosis factor therapy for rheumatoid arthritis patients who have failed their first anti-tumor necrosis factor therapy? Comparative analysis from the British Society for Rheumatology Biologics Register. Arthritis Care Res. 2012;64(8):1108-15. doi:10.1002/acr.21663.

14. Sullivan SD, Alfonso-Cristancho R, Carlson J, Mallya $U$, Ringold $S$. Economic consequences of sequencing biologics in rheumatoid arthritis: a systematic review. J Med Econ. 2013;16(3):391-6. doi:10.3111/13696998.2013.763812.

15. Marchesoni A, Zaccara E, Gorla R, Bazzani C, Sarzi-Puttini P, Atzeni F, et al. TNF-alpha antagonist survival rate in a cohort of rheumatoid arthritis patients observed under conditions of standard clinical practice. Ann N Y Acad Sci. 2009;1173:837-46. doi:10.1111/j.1749-6632.2009. 04621.x.

16. Leffers HC, Ostergaard M, Glintborg B, Krogh NS, Foged H, Tarp U, et al. Efficacy of abatacept and tocilizumab in patients with rheumatoid arthritis treated in clinical practice: results from the nationwide Danish DANBIO registry. Ann Rheum Dis. 2011;70(7):1216-22. doi:10.1136/ard.2010.140129.

17. Simard JF, Arkema EV, Sundstrom A, Geborek P, Saxne T, Baecklund E, et al. Ten years with biologics: to whom do data on effectiveness and safety apply? Rheumatology (Oxford). 2011;50(1):204-13. doi:10.1093/rheumatology/keq326.

18. Frazier-Mironer A, Dougados $\mathrm{M}$, Mariette $\mathrm{X}$, Cantagrel A, Deschamps V, Flipo RM, et al. Retention rates of adalimumab, etanercept and infliximab as first and second-line biotherapy in patients with rheumatoid arthritis in daily practice. Joint Bone Spine. 2014;81(4):352-9. doi:10.1016/j.jbspin.2014. 02.014 .

19. Nam JL, Ramiro S, Gaujoux-Viala C, Takase K, Leon-Garcia M, Emery P, et al. Efficacy of biological disease-modifying antirheumatic drugs: a systematic literature review informing the 2013 update of the EULAR recommendations for the management of rheumatoid arthritis. Ann Rheum Dis. 2014;73(3):516-28. doi:10.1136/annrheumdis2013-204577.

20. Grijalva CG, Chung CP, Arbogast PG, Stein CM, Mitchel EF Jr, Griffin MR. Assessment of adherence to and persistence on disease-modifying antirheumatic drugs (DMARDs) in patients with rheumatoid arthritis. Med Care. 2007;45(10 Supl 2):S66-76. doi:10.1097/MLR.0b013e318041384c.

21. Tang B, Rahman M, Waters HC, Callegari P. Treatment persistence with adalimumab, etanercept, or infliximab in combination with methotrexate and the effects on health care costs in patients with rheumatoid arthritis. Clin Ther. 2008;30(7):1375-84.

22. Wu E, Chen L, Birnbaum H, Yang E, Cifaldi M. Retrospective claims data analysis of dosage adjustment patterns of TNF antagonists among patients with rheumatoid arthritis. Curr Med Res Opin. 2008;24(8):2229-40. doi:10.1185/ 03007990802229548 .

23. Curkendall S, Patel V, Gleeson M, Campbell RS, Zagari M, Dubois R. Compliance with biologic therapies for rheumatoid arthritis: do patient outof-pocket payments matter? Arthritis Rheum. 2008;59(10):1519-26. doi:10.1002/art.24114.

24. Borah BJ, Huang X, Zarotsky V, Globe D. Trends in RA patients' adherence to subcutaneous anti-TNF therapies and costs. Curr Med Res Opin. 2009;25(6):1365-77. doi:10.1185/ 03007990902896386.

25. Yazici Y, Krasnokutsky S, Barnes JP, Hines PL, Wang J, Rosenblatt L. Changing patterns of tumor necrosis factor inhibitor use in 9074 patients with rheumatoid arthritis. J Rheumatol. 2009;36(5):907-13. doi:10.3899/jrheum.080592.

26. Blum MA, Koo D, Doshi JA. Measurement and rates of persistence with and adherence to biologics for rheumatoid arthritis: a systematic review. Clin Ther. 2011;33(7):901-13. doi:10.1016/j.clinthera. 2011.06.001.

27. Kremer JM. The CORRONA database. Autoimmun Rev. 2006;5(1):46-54. doi:10.1016/j.autrev.2005. 07.006.

28. CORRONA: Data to empower. 2014. http://www. corrona.org. Accessed 01 Dec 2014.

29. Velentgas P, Dreyer NA, Nourjan P, Smith SR, Torchia MM. Developing a protocol for observational comparative effectiveness research: a user's guide. AHRQ Publication No. 12(13)-EHC099. Rockville: Agency for Healthcare Research and Quality; January 2013. http://www.effectivehealthcare.ahrq.gov/ Methods-OCER.cfm2013. Accessed 01 Dec 2014.

30. Singh JA, Furst DE, Bharat A, Curtis JR, Kavanaugh AF, Kremer JM, et al. 2012 update of the 2008 American College of Rheumatology recommendations for the use of disease-modifying 
antirheumatic drugs and biologic agents in the treatment of rheumatoid arthritis. Arthritis Care Res (Hoboken). 2012;64(5):625-39. doi:10.1002/ acr.21641.

31. Furst DE, Keystone EC, So AK, Braun J, Breedveld FC, Burmester GR, et al. Updated consensus statement on biological agents for the treatment of rheumatic diseases, 2012. Ann Rheum Dis. 2013;72(Suppl 2):ii2-34. doi:10.1136/ annrheumdis-2013-203348.

32. Rendas-Baum R, Wallenstein GV, Koncz T, Kosinski M, Yang M, Bradley J, et al. Evaluating the efficacy of sequential biologic therapies for rheumatoid arthritis patients with an inadequate response to tumor necrosis factor-alpha inhibitors. Arthritis Res Ther. 2011;13(1):R25. doi:10.1186/ar3249.

33. Genovese MC, Becker JC, Schiff M, Luggen M, Sherrer Y, Kremer J, et al. Abatacept for rheumatoid arthritis refractory to tumor necrosis factor alpha inhibition. N Engl J Med. 2005;353(11):1114-23. doi:10.1056/NEJMoa050524.

34. Cohen SB, Emery P, Greenwald MW, Dougados M, Furie RA, Genovese MC, et al. Rituximab for rheumatoid arthritis refractory to anti-tumor necrosis factor therapy: Results of a multicenter, randomized, double-blind, placebo-controlled, phase III trial evaluating primary efficacy and safety at twenty-four weeks. Arthritis Rheum. 2006;54(9):2793-806. doi:10.1002/art.22025.

35. Emery P, Keystone E, Tony HP, Cantagrel A, van Vollenhoven VR, Sanchez A, et al. IL-6 receptor inhibition with tocilizumab improves treatment outcomes in patients with rheumatoid arthritis refractory to anti-tumour necrosis factor biologicals: results from a 24-week multicentre randomised placebo-controlled trial. Ann Rheum Dis. 2008;67(11):1516-23. doi:10.1136/ard.2008. 092932 .

36. Burmester GR, Blanco R, Charles-Schoeman C, Wollenhaupt J, Zerbini C, Benda B, et al. Tofacitinib (CP-690,550) in combination with methotrexate in patients with active rheumatoid arthritis with an inadequate response to tumour necrosis factor inhibitors: a randomised phase 3 trial. The Lancet. 2013;381(9865):451-60. doi:10.1016/s01406736(12)61424-X.

37. van den Hoek J, Roorda LD, Boshuizen HC, van Hees J, Rupp I, Tijhuis GJ, et al. Long term physical functioning and its association with somatic comorbidity and comorbid depression in patients with established rheumatoid arthritis: a longitudinal study. Arthritis Care Res (Hoboken). 2013;65:1157-65. doi:10.1002/acr.21950.

38. Curtis JR, Chen L, Bharat A, Delzell E, Greenberg JD, Harrold L, et al. Linkage of a de-identified United States rheumatoid arthritis registry with administrative data to facilitate comparative effectiveness research. Arthritis Care Res (Hoboken). 2014;66(12):1790-8. doi:10.1002/acr.22377.

39. Chatzidionysiou K, Askling J, Eriksson J, Kristensen LE, van Vallenhoven R. Effectiveness of TNF inhibitor switch in RA: results from the national Swedish register. Ann Rheum Dis. 2015;74(5):890-6. doi:10.1136/annrheumdis-2013-204714. 